fusion of chromium into the plate. This process is speeded by the presence of the palladium as previously explained. Some chromium diffuses through to the surface where it forms a green oxide. This can be seen in Figure 8 as an outer layer which has become detached from the gold-palladium during the specimen preparation. This thin layer of chromium oxide is no detriment and may be an additional barrier to nitrogen entry.

\section{Gas Turbine Conditions}

A standard test for evaluating the thermal shock resistance of materials for gas turbine engines comprises a spinning rig which rotates bars $85 \mathrm{~mm}$ long, $7.0 \mathrm{~mm}$ diameter, supported in a cage, in and out of a gas jet which cycles the specimen temperature up to $1100^{\circ} \mathrm{C}$, simulating conditions in a gas turbine. A set of chromium alloy bars containing 1 per cent zirconium, 0.2 per cent boron, 1.2 per cent yttrium and 1.0 per cent cerium were coated with gold and gold-palladium in the manner already described.

The coatings all withstood the test, which was carried out at a nominal temperature of $1100^{\circ} \mathrm{C}$ for 48 hours. The coatings were not melted or eroded away, except for a small part of one of the pure gold samples. There were 15 shut-downs during the test run.

Micrographs of the gold-palladium coatings after this test are similar to those in static conditions. Figures 9 and 10 show the coatings at the centre of the bars exposed in the rig. Figure 9 has a gold only coating and Figure 10, a gold +10 per cent palladium coating.
Although it would appear from the unmelted condition of the pure gold coatings that $1100^{\circ} \mathrm{C}$ was not attained, the test was a standard one for simulating gas turbine flame conditions at this nominal temperature. The fact that the coatings have not been eroded or blown off shows that the system is a practical one and merits testing in an actual operating turbine or simulative cascade.

\section{Conclusion}

The nitridation of chromium-base alloys can be considerably retarded by suitably applied gold plating. For temperatures above the melting point of gold, an alloy plate of gold and palladium has been shown to be effective.

Little diffusion of gold into the base metal occurs so that the coating is effective over long periods. Alloying the gold with palladium raises the maximum temperatures to which the coating can be used but also increases diffusion of chromium into the protective layer which therefore slowly increases in thickness. On reaching the outside, the chromium forms a green oxide layer. Considerable reduction in the transition temperature is achieved compared with unprotected chromium or chromium alloys.

Alloys coated by this process withstood gas turbine blade conditions. The development of this protective treatment removes one of the hindrances delaying the use of chromium-base alloys for high strength, high temperature applications.

An application for a patent covering the process described has been made.

\title{
Single Crystals of Gold Monochloride
}

The monochloride of gold, $\mathrm{AuCl}$, has for long been known as an elusive and transitory substance. Although methods for its preparation have occasionally been given, it is unstable in air and quickly dissociates into its constituent elements. Its crystal structure has therefore never been established. Recently, however, E. M. W. Janssen, J. C. W. Folmer and G. A. Wiegers of the Laboratorium voor Anorganische Chemie at Groningen in the Netherlands have, by studying the thermodynamical data, been successful in preparing quite large single crystals of $\mathrm{AuCl}$, storing them in chlorine at atmospheric pressure in sealed glass tubes at $-20^{\circ} \mathrm{C}$, and measuring their crystal properties ( $F$. Less-Common Metals, 1974, 38, (1), 71-76).

The method of preparation was by vapour transport by way of gaseous $\mathrm{Au}_{2} \mathrm{Cl}_{8}$ in chlorine. First a supply of solid $\mathrm{Au}_{2} \mathrm{Cl}_{6}$ was formed by the reaction of very fine reactive gold powder with chlorine in a quartz tube at $235^{\circ} \mathrm{C}$. The chlorine above the solid in the tube was naturally saturated with gaseous $\mathrm{Au}_{2} \mathrm{Cl}_{6}$, which at this temperature exerted a partial pressure of rather more than 3.8 Torr. The thermodynamic data showed that at a slightly higher temperature the partial pressure of gaseous $\mathrm{Au}_{2} \mathrm{Cl}_{6}$ in chlorine above solid $\mathrm{Au}_{2} \mathrm{Cl}_{6}$ rapidly falls. While, for instance, at $250^{\circ} \mathrm{C}$ it is $3.8 \mathrm{Torr}$, at $280^{\circ} \mathrm{C}$ it is only 2.5 Torr; and the reduction in partial pressure is achieved by deposition of solid $\mathrm{AuCl}$. Accordingly, after forming the solid $\mathrm{Au}_{2} \mathrm{Cl}_{6}$, a temperature gradient of about $25^{\circ} \mathrm{C}$ was set up in the quartz tube, the pressure of chlorine being maintained at one atmosphere. After about a week, half of the $\mathrm{Au}_{2} \mathrm{Cl}_{6}$ solid was transported to the hotter part of the tube, where crystals of $\mathrm{AuCl}$ up to $8 \times 3 \times 3 \mathrm{~mm}$ in size were deposited.

Powder from the crystals was sealed in glass capillaries and examined by $\mathrm{X}$-ray crystallography. $\mathrm{AuCl}$ is shown to be tetragonal, with $a=6.734$ and $c=$ $8.674 \AA$. The structure consists of zig-zag chains of gold and chlorine atoms, with chlorine atoms at the apex points joined to each other by intermediate gold atoms, the interatomic spacing being $2.36 \AA$. The zigzag angle $\mathrm{Au}-\mathrm{Cl}-\mathrm{Au}$ is $92^{\circ}$. The chains run parallel to the $b$ - and $a$-axes.

J. c. C. 